\title{
An evaluation of the technique of use of metered dose inhaler administration in bronchial asthma children
}

\author{
Mustak M. Makarani ${ }^{1}$, Prakruti P. Patel ${ }^{2 *}$, Anuradha M. Gandhi ${ }^{2}$, \\ Chetna K. Desai ${ }^{1}$, Mira K. Desai ${ }^{3}$
}

\author{
${ }^{1}$ Apcer Life Science, Ahmedabad, Gujarat, India \\ ${ }^{2}$ Department of Pharmacology, B. J. Medical College, Ahmedabad, Gujarat, India \\ ${ }^{3}$ Department of Pharmacology, Nootan Medical College, Visnagar, Gujarat, India
}

Received: 17 January 2020

Revised: 14 July 2020

Accepted: 14 August 2020

\section{*Correspondence:}

Dr. Patel Prakruti P.,

Email: prakrutiparth@yahoo.co.in

Copyright: (c) the author(s), publisher and licensee Medip Academy. This is an open-access article distributed under the terms of the Creative Commons Attribution Non-Commercial License, which permits unrestricted non-commercial use, distribution, and reproduction in any medium, provided the original work is properly cited.

\begin{abstract}
Background: Inadequate understanding and performance of drug administration using metered-dose inhaler (MDI) in paediatric population affects therapeutic outcome. Hence, this study aimed to evaluate the impact of two educational interventional methods for usage of MDI in paediatric patients of bronchial asthma.

Methods: This prospective, interventional study was done in paediatric asthma patients who were prescribed drugs with (MDI) with/without spacer at outpatient department of pediatrics. Patients were divided in group A (video) or group B (leaflet) as per random table method and method to use MDI was assessed by using checklist as per WHO guide to good prescribing at baseline. Investigator taught the technique by a video (group A) and leaflet (group B) to the selected population. Patients were followed up after 15 days and assessed for use of MDI using the same checklist. Data were analysed by using paired and unpaired ' $t$ '-test.

Results: A total of 100 pediatric asthma patients were included in study group A (50) and group B (50). The average no. of steps (WHO checklist) followed was significantly improved at post intervention in both group A (with spacer, $\mathrm{p}<0.0001$ ) as well as B (without spacer, $\mathrm{p}<0.05$ ). Although average no. of steps followed were more in group A, no significant difference was found between two groups after intervention.

Conclusions: As video is an audio-visual method of demonstration, and hence help us memorise the step of inhalational technique in pediatric patients. Repeated demonstration/education to patients/caregivers may improve the method of MDI usage.
\end{abstract}

Keywords: Metered dose inhaler (MDI), Bronchial asthma, Pediatric patients

\section{INTRODUCTION}

Bronchial asthma is a common, chronic inflammatory disorder of the airways associated with airway hyperresponsiveness. In children, asthma exacerbations are a leading cause of hospitalization and is responsible for elementary school absenteeism. ${ }^{1-3}$
Asthma is observed more common in children due to various factors like family history of asthma, allergic rhinitis, having smokers as parents, urban place of residence and early weaning from maternal breast milk. ${ }^{4}$ At the age of six to seven years, the prevalence ranges from 4 to $32 \% .^{5}$

Metered dose inhaler (MDI) is the most common device used in daily asthmatic management; it is portable, 
quicker to be used, and less expensive. MDI requires patients to coordinate inhalation along with activation of the device, which can be difficult. Proper use of the inhaler as well as use of an appropriate dose schedule, is important to achieving the benefits of the medications. ${ }^{6}$ As children are at developing stages of both physical and cognitive function, it is difficult for children to understand the complex steps of inhalation and hence are not able to perform all the steps of MDI administration properly as compared to adults. Also, poor education of patients/caretakers can influence drug delivery and thus potentially reduce its efficacy. ${ }^{7}$

\section{Table 1: Steps required for proper MDI-spacer use} are following.

\begin{tabular}{|c|c|}
\hline MDI & MDI-spacer \\
\hline $\begin{array}{l}\text { Cough up as much } \\
\text { sputum as possible }\end{array}$ & Assemble spacer \\
\hline $\begin{array}{l}\text { Shake the aerosol } \\
\text { before use * }\end{array}$ & Remove inhaler cap \\
\hline $\begin{array}{l}\text { Hold the aerosol as } \\
\text { indicated in the } \\
\text { manufacturer's } \\
\text { instructions (this is } \\
\text { usually upside down) }\end{array}$ & $\begin{array}{l}\text { Hold inhaler upright and } \\
\text { shake well }\end{array}$ \\
\hline \multirow{2}{*}{$\begin{array}{l}\text { Place the lips tightly } \\
\text { around the } \\
\text { mouthpiece } *\end{array}$} & $\begin{array}{l}\text { Insert inhaler upright into } \\
\text { spacer }\end{array}$ \\
\hline & $\begin{array}{l}\text { Put mouthpiece between } \\
\text { teeth without biting and } \\
\text { close lips to form good seal }\end{array}$ \\
\hline $\begin{array}{l}\text { Tilt the head } \\
\text { backward slightly }\end{array}$ & Breathe out gently \\
\hline $\begin{array}{l}\text { Breathe out slowly, } \\
\text { emptying the lungs of } \\
\text { as much air as } \\
\text { possible * }\end{array}$ & $\begin{array}{l}\text { Hold spacer level and press } \\
\text { down firmly on canister } \\
\text { once }\end{array}$ \\
\hline $\begin{array}{l}\text { Breathe in deeply and } \\
\text { activate the aerosol, } \\
\text { keeping the tongue } \\
\text { down }\end{array}$ & $\begin{array}{l}\text { Breathe in slowly and } \\
\text { deeply }\end{array}$ \\
\hline $\begin{array}{l}\text { Hold the breath for } \\
\text { ten to fifteen seconds* }\end{array}$ & $\begin{array}{l}\text { Hold breath for about } 5-10 \\
\text { seconds or as long as } \\
\text { comfortable }\end{array}$ \\
\hline $\begin{array}{l}\text { Breathe out through } \\
\text { the nose } *\end{array}$ & $\begin{array}{l}\text { While holding breath } \\
\text { remove spacer from mouth }\end{array}$ \\
\hline \multirow[t]{4}{*}{$\begin{array}{l}\text { Rinse the mouth with } \\
\text { warm water }\end{array}$} & $\begin{array}{l}\text { Breath out gently away from } \\
\text { mouthpiece }\end{array}$ \\
\hline & Remove inhaler from spacer \\
\hline & $\begin{array}{l}\text { If an extra dose is needed, } \\
\text { wait } 1 \text { minute and then } \\
\text { repeat steps } 3 \text { to } 12\end{array}$ \\
\hline & $\begin{array}{l}\text { Replace cap and } \\
\text { disassemble spacer }\end{array}$ \\
\hline
\end{tabular}

*Suggests essential steps. ${ }^{8,9}$

Proper technique of use of MDIs has proven to be associated with good control of the bronchial asthma and other pulmonary conditions. ${ }^{10}$ Educational initiatives to teach the use of MDI can be helpful to improve rates of proper inhalational device. ${ }^{11}$ It can also be helpful to create awareness about the complications of improper technique. ${ }^{12}$ Different educational methods for MDI administration technique include verbal and written instructions, physical demonstration, illustrations, audiovisual demonstration and internet based interactive, multimedia tutorials. ${ }^{13}$

In pediatric patients, there are very few studies done to evaluate the deficiencies in the technique of use of MDI with or without spacer. The information received from such type of studies is very essential to guide the patients regarding the lacking step of MDI inhalation. Also, routine methods may use in adults be insufficient to teach children. Hence, this study was under taken to evaluate the technique of using metered dose inhaler in pediatric population and to compare the effect of two different educational interventional techniques on the use of meter dose inhaler in pediatric patients of asthma at a tertiary health care hospital.

\section{METHODS}

This was a prospective, continuous, interventional, comparative study conducted in the pediatric patients diagnosed to have bronchial asthma and who were prescribed anti-asthmatic drugs in the form of MDI at outpatient department of pediatrics civil hospital, Ahmedabad. Before starting the study, prior permission was taken from the Institutional Ethics Committee and Head of the Department of Pediatrics, Civil Hospital, Ahmedabad. Pediatric patients (up to 12 years.) who were diagnosed to have asthma and were prescribed drugs in the form of inhalational agents by using metered dose inhaler (MDI) and who were willing to participate in the study were included after taking informed consent from caregivers. Patients/caregivers unable to interpret the technique, having respiratory disease other than asthma and who were not prescribed drugs by using MDI were excluded from the study the study was divided in preinterventional, interventional and post-interventional phase. During pre-interventional phase, the investigator attended the outpatient department of pediatrics department of civil hospital, Ahmedabad. The patients who met with the inclusion and exclusion criteria were enrolled for the study. The demographic details like age, gender, educational status, duration of disease, duration of treatment, details of the drug treatment and frequency of hospitalization were recorded. The patient's/caregiver's knowledge about disease, frequency of demonstration by the doctor and method of demonstration was also recorded. The steps of inhalational technique were evaluated by asking patient with or without help of caregivers to show the method of inhalation with the help of MDI with or without spacer. Patients were provided with empty canister by investigator to show the steps of inhalational technique. The data was recorded in a detailed case record form $(\mathrm{CRF})$ and were scored as per the recommendation given 
by guide to good prescribing - World Health Organisation (WHO). A total of 10 steps are assigned by WHO for an ideal MDI administration technique, among which 5 are essential steps, whereas for MDI with spacer a total of 14 steps are assigned. administration technique. Patients were scored 1 for correct method and scored 0 for wrong method for every step. So maximum score was 10 for MDI without spacer and 14 for MDI with spacer. After 2 weeks, the same patients who were included in the study were subjected to the interventional phase, in this phase the patients were randomised in two groups i.e., group A and group B using computer generated random table method. In group A, investigator taught the technique of use of MDI for drug administration by showing video to the patient. The video showing the details of each step of the technique of MDI administration which was made by investigator himself. The patient was answered to every query that aroused. In group B, the investigator showed a leaflet having pictures and instructions which explained every step-in detail, regarding using MDI administration. The leaflet and video were prepared by investigator in three different languages (Hindi, English, Gujarati) and validated by 5 pharmacologist and 5 lay persons. The patients were free to ask any query about use of MDI for drug administration. After 15 days, patients were asked to come for the post-intervention and subjected to the postinterventional phase, in this phase the same patients were asked to demonstrate the steps of using MDI with or without spacer administration and were scored using WHO guidelines. All the recorded data were analysed by using graph pad software version 3.06 and data was analyzed using paired and unpaired t-test.

\section{RESULTS}

This was an interventional study carried out on the pediatric patients suffering from bronchial asthma and who were prescribed drugs using MDI with or without spacer. A total 100 patients were included in the study and were divided into two groups by a computergenerated random table method. In group $\mathrm{A}$, investigator taught the technique of using MDI administration by showing a video to the patient while in group B, this was done by using a leaflet containing pictures and instructions. In each of group A and B, 50 patients were included for the study. The mean age of patients was $6.66 \pm 0.35$ years in group $\mathrm{A}$ and $7.53 \pm 1.027$ years in group B. Boy: girl ratio was 2.33:1 in group A and 1.94:1 in group B. The duration of diagnosis of disease was $3.94 \pm 0.3$ years in group A and 3.69 \pm 0.34 years in group $B$. The duration of treatment was $2.93 \pm 0.22$ years and $2.82 \pm 0.31$ years in group A and B respectively. There was no significant difference amongst both groups for age, duration of diagnosis and duration of treatment. Commonly prescribed drugs in both groups were levosalbutamol MDI and budesonide MDI followed by fluticasone propionate and formoterol fumarate. Table 2 shows the demographic details of the enrolled patients during study period.
MDI technique was taught by the physician to all patients in both group $\mathrm{A}$ and $\mathrm{B}$ by demonstration technique at the time the drugs were initially prescribed. Among them the average frequency of demonstration was $1.22 \pm 0.05$ and $1.24 \pm 0.06$ times per year in group A and B respectively. Patients who had actually performed the technique in front of the physician were $28(56 \%)$ from group A and $23(46 \%)$ from group B.

The average number of steps followed by patients using MDI (without spacer) in group A were $6.84 \pm 0.19$ at postintervention phase as compared to $4.20 \pm 0.16$ in the pre intervention phase for which $\mathrm{p}$ value was $<0.0001$ which was significant. At pre-intervention, $30.18 \%$ of total essential steps were followed by patients in group A which were increased to $59.54 \%$ during post intervention. In group $\mathrm{A}$, in patients using MDI (without spacer), the least followed step was step 1 (cough up as much sputum as possible before starting the inhalation) and step 10 (rinse the mouth with warm water) at pre intervention which increased to $55 \%$ in step 1 and $32.6 \%$ in step 10 at post intervention (Figure 1) in group A. At pre intervention, step 1, 2, 5, 6, 8 and 10 were followed by less than $50 \%$ of patients in group A which were increased during post intervention. However even at the post intervention, step 6,8 and 10 were followed by $<50 \%$ of the patients.

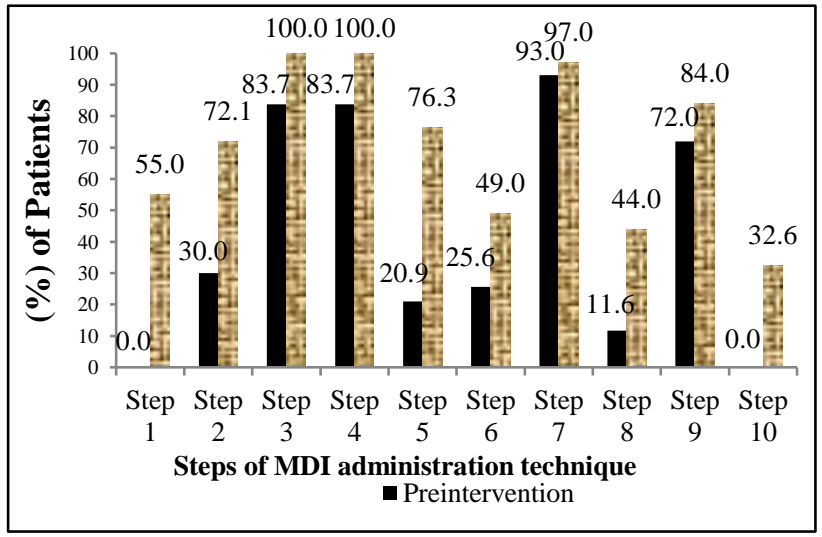

Figure 1: Steps of MDI (without spacer) administration technique followed by patients at the pre-intervention and post-intervention in group $A$ $(n=43)$.

The average steps followed by patient using MDI (without spacer) in group $\mathrm{B}$, at post intervention were $6.63 \pm 0.20$ as compared to $4.31 \pm 0.18$ in the pre intervention phase for which $\mathrm{p}$ value was $<0.0001$ which was significant. $45.78 \%$ of total essential steps were followed by patients in group B which were increased to $63.6 \%$ during post intervention. In group $\mathrm{B}$ at pre intervention in patient using MDI (without spacer), least followed steps were step 1 (cough up as much sputum as possible) and step10 (rinse the mouth with warm water) while after intervention it increased to $39.5 \%$ and $29 \%$ respectively (Figure 2). 
Table 2: Demographic details of the pediatric patients at outpatient department of $\mathrm{CHA}(\mathrm{n}=100)$.

\begin{tabular}{|llll|}
\hline Title & Group A (video) & Group B (leaflet) & P value \\
\hline No. of patients & 50 & 50 & - \\
\hline Boy: girl ratio & $2.33: 1$ & $1.94: 1$ & - \\
\hline Mean age (years) & $6.66 \pm 0.35($ mean \pm SEM) & $7.53 \pm 1.027$ (mean \pm SEM) & $<0.05$ \\
\hline Mean duration of disease (years) & $3.94 \pm 0.3$ (mean \pm SEM) & $3.69 \pm 0.34$ (mean \pm SEM) & $<0.05$ \\
\hline
\end{tabular}

At pre intervention, step 1, 2, 5, 6, 8 and 10 were followed by less than $50 \%$ of patients in group B which were increased during post intervention. However, in the post intervention also, step 1, 6, 8 and 10 were followed by $<50 \%$ of the patients.

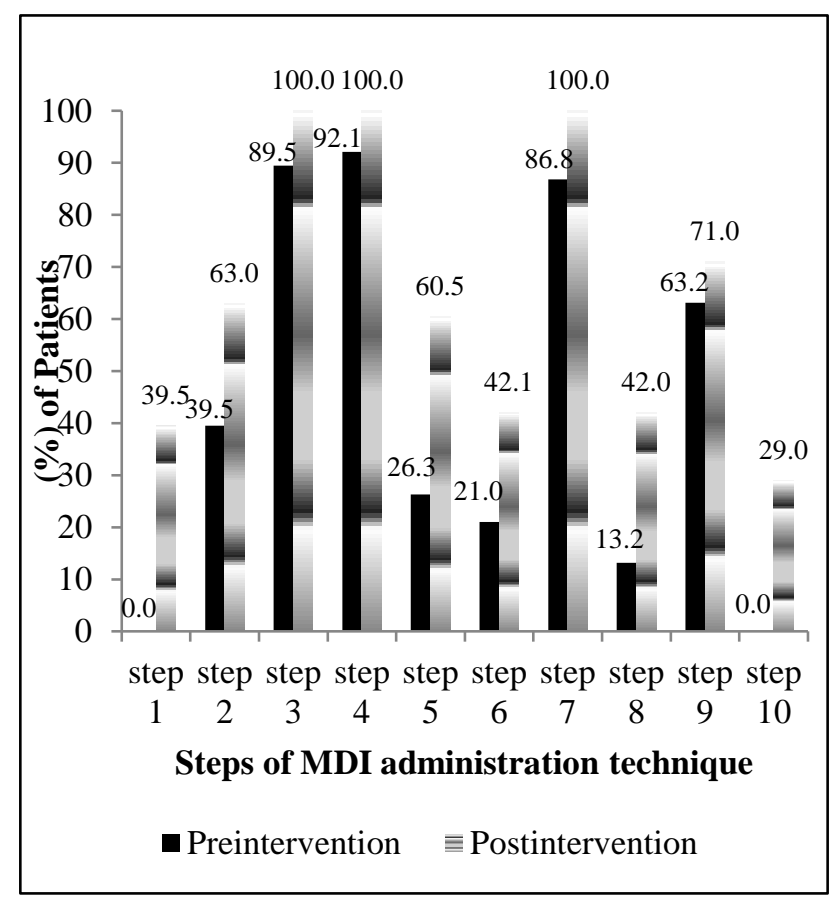

Figure 2: Steps of MDI (without spacer) administration technique followed by the patients at the pre-intervention and post-intervention in group $B$ $(n=38)$.

When group A and B were compared, it was observed that the average steps followed in patients using MDI (without spacer) at pre-intervention in group A and B was $4.20 \pm 0.16$ and $4.31 \pm 0.18$ respectively for which unpaired t-test was applied and $p$ value was 0.6645 which was not significant. The average no. of steps followed in patients using MDI (without spacer) at the post-intervention in group $\mathrm{A}$ and $\mathrm{B}$ were $6.83 \pm 0$. and $6.63 \pm 0.20$ respectively. There was no significant difference in the average number of steps followed by patients of group A and B at post intervention with $\mathrm{p}$ value 0.4749 using unpaired $\mathrm{t}$ test.

In group A no patients followed all the 10 steps at preintervention while 2 patients followed all the 10 steps at post-intervention. In group $\mathrm{B}$, no patient followed all the 10 steps before or after intervention
In group A the average steps followed at pre-intervention were $8.14 \pm 0.59$ which increased to $11.71 \pm 0.56$ in the post $(\mathrm{p} \leq 0.0001)$ which was significant. Step $1,2,12$ and 14 were followed by all the patients at pre and post intervention in group A. At pre intervention, step 3, 6, 9, 10,11 and 13 were followed by less than $50 \%$ of patients in group A which were increased during post intervention. While at post intervention also step 6 and 9 were followed by $<50 \%$ of the patients.

In group $\mathrm{A}$, in patients using MDI (with spacer) at preintervention, no patient followed steps step 6 (breath out gently) and step 9 (hold breath for about 5-10 seconds or as long as possible) in group A while after intervention it increased to $28.57 \%$ and $42.8 \%$ respectively. The most improved steps in group A were step-3 (hold inhaler upright and shake well) and step 13 (if an extra dose needed wait 1 minute and then repeat step 3 to 12) (Figure 3).

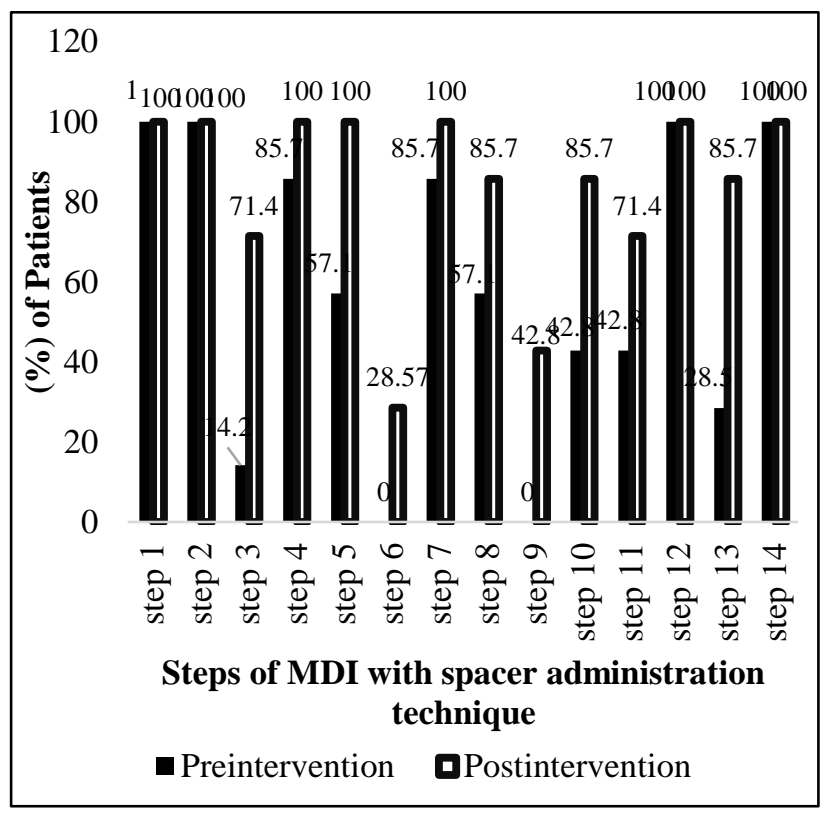

Figure 3: Steps of MDI with spacer administration technique followed by patients at the pre-intervention and post-intervention in group $A(n=7)$.

In group B (MDI with spacer) the average steps followed at pre-intervention were $8.25 \pm 0.39$ which increased to $11.41 \pm 0.28$ in the post-intervention $(\mathrm{p} \leq 0.0001)$ which was significant. Step 1, 2, 12 and 14 were followed by all the patients at pre and post intervention in group B. At pre intervention, step 3, 6, 9, 10, 11 and 13 were followed 
by less than $50 \%$ of patients in group B which were increased during post intervention. While at post intervention also, step 6 and 9 were followed by $<50 \%$ of the patients.

In group B at pre intervention in patient using MDI (with spacer), least followed steps in group B were step 6 $(5.8 \%)$ (breath out gently) and step $9(0 \%)$ (hold breath for about 5-10 seconds or as long as possible) while after intervention it increased to $45.5 \%$ and $45.4 \%$ respectively. The most improved steps in group B were step-3 (58.33\%) (hold inhaler upright and shake well) and step $13(75 \%)$ (If an extra dose needed wait 1 minute and then repeat step 3 to 12) (Figure 4). None of the patients from either group A or B followed all the 14 steps before or after intervention.

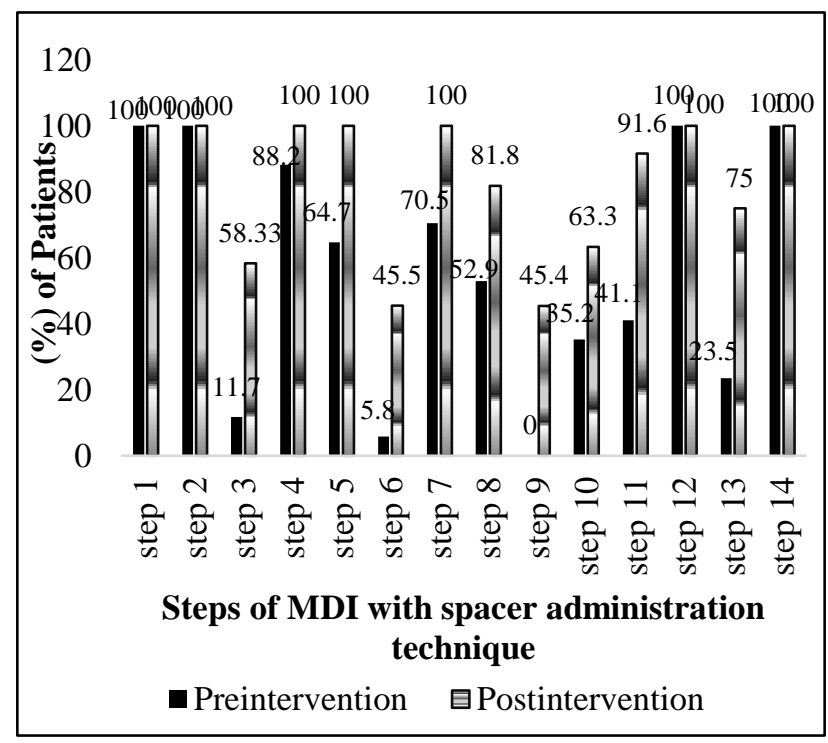

Figure 4: Steps of MDI with spacer administration technique followed by patients at the pre-intervention and post-intervention in group $B(n=12)$.

When the correlation between age and duration of disease with mean difference of step followed was done it was found that there was no correlation found between age $\left(\mathrm{r}^{2}\right.$ value $=0.0017)$ as well as duration of disease $\left(r^{2}\right.$ value $=0.0008$ ) with mean number of steps.

\section{DISCUSSION}

The inhalation route is widely used for the treatment of bronchial asthma. Up to $76 \%$ of patients make some type of error in their inhaler technique. ${ }^{14}$ An effective use of an inhaler device assures delivery of the drug to the airways. One of the most important disadvantages of aerosol drug therapy, is that specific inhalation techniques are necessary for the proper use of each of the available types of inhaler device. This is particularly important in pediatric patients, in whom it is further difficult to teach the proper technique of MDI administration. Usage of MDI required synchronization between pressing the canister and at the same time taking deep breath. This is very difficult to perform by children particularly less than 5 year of age. So, spacers are also used with MDI in pediatric population to overcome this problem. In Indian scenario, MDI administration technique is taught by demonstration method by the clinicians. The frequency of demonstration is also less than once a year. ${ }^{18}$ Most of the patient or caregivers are educated about the technique only during the initial stage of disease without much repeated counselling. Poor education of the patient/caretakers may also affect the outcome of technique of MDI use. Several studies have focused on effects of demonstration on people's ability to use inhalers. Heringa et al considered both the knowledge and psychomotor skills of the patients and concluded that a structured teaching of right technique is an effective method for improving skills regarding the use of inhaler with or without spacer. ${ }^{15}$ Studies are done in adult population to evaluate different methods to teach the technique of the MDI. Very few studies are done in pediatric population to study the effect of different education intervention to teach the technique of using MDI. ${ }^{18}$

This study aimed to evaluate the technique of use of MDI (with or without spacer) and to assess the effect of two different educational intervention i.e. video vs leaflet on the inhalation technique as per materials and methods. Patients were divided into two groups and 50 patients were included in each group. In group A, steps of inhalation technique were taught to the patients or caregivers by showing video while in group B it was taught by showing leaflet containing written instructions in group B. Both of the methods are cheap, convenient and easy to understand.

In our study, at the pre-intervention phase, proper inhalation technique was lacking in all pediatric asthma patients. In our study, all patients $(100 \%)$ were instructed regarding the use of inhaler by treating physician which is more than that reported by Larsen et al (63\%) and Jolly et al $(58.8 \%)$ study. ${ }^{16,17}$ This suggest that the demonstration of the technique of use of MDI at initial stage is essential part of successful asthma management.

At pre-intervention none of the patients correctly performed all the ten steps of MDI (without spacer) administration (10/10score) as per WHO checklist. Most commonly followed steps in group A were step 3 and 7 which are holding the aerosol as indicated in the manufacturer's instruction and breathe in deeply and activate the aerosol, keeping the tongue down while in group B, step 3 and 4 which are holding the aerosol as indicated in the manufacturer's instruction and placing the lips tightly around the mouthpiece were most commonly followed steps. This might be due the reason that this step is easy to understand and perform by the pediatric patients. Least followed steps in group A were step $1,10,5$ and 8 which are cough up as much sputum 
as possible, rinse the mouth with warm water, tilt the head backward slightly, and hold the breath for ten to fifteen seconds, respectively. In group B, least followed step was step 1, 10, 6 and 8 which are cough up as much sputum as possible, rinse the mouth with warm water, breathe out slowly, emptying the lungs of as much air as possible, and hold the breath for ten to fifteen seconds. Steps like hold the breath for ten to fifteen seconds are difficult to demonstrate by physician and moreover difficult to understand by the pediatric patients. Steps like rinse the mouth with warm water are associated with the unavailability of warm water after each dosing of MDI.

Essential steps of MDI as per WHO are those which are very necessary to be performed by the patients to ensure optimal delivery of the inhalational agents. None of the patients from either group were able to follow all the essential steps of MDI use at the pre-intervention. This might be because of the reason that although physician demonstrated the technique of MDI initially, repeated demonstrations were missing. As per the history taken from patients, the average frequency of demonstration was 1.2 times per year. Repeated demonstrations are very essential for paediatrics for better remembering of steps of MDI usage. After educational intervention no significant improvement has been observed in both the groups. Only 2 patients from group A and 0 patients from group B were able to demonstrate all 5 essential steps of MDI use after intervention. This might be because of the fact that pediatric population has limitations in understanding the complex process of MDI administration technique. Essential steps like holding the breath for 10-15 seconds, placing the lips tightly around mouthpiece and breathe out gently through the nose are difficult to perform by the pediatric patients. So even after intervention it was difficult for them to remember and perform all the 5 essential steps of MDI administration. Usage of spacer might help to improve the essential steps followed by the pediatric patients. Though not all steps but individual essential steps (step 2, 4, 6, 8 and 9) followed were improved at post intervention as compared to baseline. Less improvement was found in average number of steps in pediatric patients compared to a similar study done in adult patients. ${ }^{18}$ This may be due to the reason that adults have better understanding than pediatrics in learning due to difference in cognitive development. Sensitization of the treating physicians to provide more time and detailed explanation to teach the importance of following essential steps may help to improve the overall essential steps followed by the patients. Also repeated demonstration can also be very helpful particularly in pediatric patients in whom learning is not as developed as adults.

MDI with spacer usage is guided by caregivers in most cases. In patients using MDI with spacer, at preintervention, least followed steps in video group and leaflet group were step 6 (breath out gently) and step 9 (Hold breath for about 5-10 seconds or as long as possible). This may be due to the lack of skill by pediatric patients and also due to poor knowledge of caregivers regarding use of MDI technique. After intervention also, step 6 (breath out gently) and step 9 (hold breath for about 5-10 seconds or as long as possible) were least followed steps compare to other steps. This may be due to the fact that both these steps required high level of skills and understanding of complex steps. Patients using spacer with MDI are usually less than 5 years of age. Hence it is difficult to perform such skilled steps by patients/caregivers at this age group. In patient using MDI with spacer, step 3 (hold inhaler upright and shake well) was the most improved steps after intervention in video group while in leaflet group, step 13 (If extra dose needed, wait for 1 minute and then repeat steps 3 to 12) was the most improved step at post intervention. The possible explanation for this that might be due to better understanding by the patients while demonstration with video or leaflet and also this step is easy to remember and perform. So overall, significant improvement was observed in average number of steps followed by the pediatric patients in both video or leaflet group regardless using MDI alone or with spacer. Although all essential steps were not followed by the patients in any group, remarkable improvement in essential steps followed was also observed in both video and leaflet group in patients using MDI.

There were two different educational methods used in this study. In one group, leaflets showing pictures and instructions were used to explain the patients about the technique of use of MDI (with or without spacer). While in the other group video was shown to the patients explaining the steps of MDI inhalation technique. Video is an audio-visual method of demonstration moreover it was made in all 3 languages Hindi, English, Gujarati which makes it more effective. Improvement in the technique of MDI inhalation has been observed more in video group than leaflet group. Although no significant difference has been observed between two groups, average number of steps followed were more in video group. This may be due to the fact that, some steps of MDI inhalation technique are difficult to understand by pediatric patients and requires higher skill development and understanding which are lacking in children. Hence, while showing leaflet to patients/caregivers, there may be lack of attention and understanding by simply watching images. In many cases, caregivers provide drug administration by MDI (with or without spacer). This may also affect the synchronization between various steps of MDI administration. By demonstrating the steps by video, patients/caregivers can closely observe the steps being demonstrated to them. Patient/caregivers can become more attentive and can easily observe all the steps. It will also be useful in memorising the steps easily. More importance should be given to specific steps by physician particularly in pediatric patients while demonstrating the technique. 
In our study, patients/caregivers were taught once about correct MDI inhalation technique during intervention phase. There was significant improvement in average no of steps followed by patients/caregivers after one session. This suggests that the repeated demonstration by physician will be very helpful to the patients/caregivers for better understanding of the steps of MDI administration. Video can also be helpful by means of saving time of physician. A mobile application can be made to teach the technique of MDI usage and frequently view at home which can make procedure very effective. Physician does not need to make repeated demonstration of steps of inhalational technique. This study also provides the information about the common mistakes done by pediatric patients and their caregivers during MDI administration. It can be useful to physicians to give more importance to the common mistakes made by pediatric patients/caregivers at the time of demonstration.

There are some limitations in this study. We included 100 pediatric asthma patients using MDI with or without spacer. Larger sample size would have been more helpful. Patients using dry powder inhalers were not included in the study. All the patients using MDI were included irrespective of their duration and frequency of usage. In this study, patients/caregivers were taught only once. More teaching sessions would have been helpful to give effective drug delivery and better patient outcome.

\section{CONCLUSION}

Improper inhalational technique greatly affects the optimal drug delivery to the patients. As children are at developing stage of physical and mental growth, they have high rate of improper MDI administration due to difficulty in understanding the complex process of MDI administration technique. As video is an audio-visual method of demonstration, children can easily memorise the step of inhalational technique by watching video. They can also watch it anytime at home. Hence audiovisual method like video can help to teach the technique of MDI inhalation more effectively. Such technique can also save time of physician. Frequent demonstration using video to the patients or caregivers can lead to improve drug delivery.

Funding: No funding sources

Conflict of interest: None declared

Ethical approval: The study was approved by the Institutional Ethics Committee

\section{REFERENCES}

1. Chronic respiratory diseases. Available at: http://www.who.int/gard/publications/chronic_respira tory_diseases.pdf. Accessed on 22 April 2014.

2. Reid J, Marciniuk DD, Cockcroft DW. Bronchial Asthma management in the emergency department. Can Respir J. 2000;7:255-60.
3. Gurkan F, Ece A, Haspolat K, Derman O, Bosnak M. Predictors for multiple hospital admissions in children with Bronchial Asthma. Can Respir J. 2000;7:163-6.

4. Majeed R, Rajar UD, Shaikh N, Majeed F, Arain AA. Risk factors associated with childhood asthma. J Coll Physicians Surg Pak. 2008;18(5):299-302.

5. Pal R, Dahal S, Pal S. Prevalence of Bronchial Asthma in Indian Children. Indian $\mathbf{J}$ Community Med. 2009;34(4):1.

6. Wilson SR, Scamagas P, German DF. A controlled trial of two forms of self-management education for adults with asthma. Am J Med. 1993;94:564-76.

7. Dolovich MB, Ahrens RC, Hess DR. Device selection and outcomes of aerosol therapy: evidencebased guidelines: American College of Chest Physicians/American College of Asthma, Allergy, and Immunology. Chest. 2005;127:335-71.

8. DeVries TPGM, Henning RH, Hogerzeil HV, Fresle DA. Guide to Good Prescribing: a practical manual; 1994. Available at: http://apps.who.int/medicinedocs /pdf/whozip23e/whozip23e.pdf. Accessed on 12 January 2020.

9. How to use a standard MDI (puffer). Available at: https://www.nationalasthma.org.au/living-withasthma/how-to-videos/how-to-use-a-standard-mdiand-spacer. Accessed on 12 January 2020.

10. Roy, Battle, Lurslurchachai, Halm, Wisnivesky. Inhaler device, administration technique, and adherence to inhaled corticosteroids in patients with asthma. Prim Care Respir J. 2011;20(2):148-54.

11. Melani A, Bonavia M, Cilenti V, Cinti C, Lodi M, Martucci $\mathrm{P}$, et al. Inhaler mishandling remains common in real life and is associated with reduced disease control. Respir Med. 2011;105:930-8.

12. Gibson PG, Ram FS, Powell H. Asthma education. Respir Med. 2003;97:1036-44.

13. Molimard M, Raherison C, Lignot S, Depont F, Abouelfath A, Moore N. Assessment of handling of inhaler devices in real life: an observational study in 3811 patients in primary care. J Aerosol Med. 2003;16(3):249-54.

14. Nimmo CJ, Chen DN, Martinusen SM, Ustad TL, Ostrow DN. Assessment of patient acceptance and inhalation technique of a pressurized aerosol inhaler and two breath-actuated devices. Annals Pharmacotherapy. 1993;27:922-7.

15. Heringa $P$, Lawson L, Reda D. The effect of structured education program on the knowledge and psychomotor skills of the patients using beclomethasone dipropionate aerosol for steroid dependent asthma. Health Educ Q. 1987;14:309-17.

16. Larsen JS, Hahn M, Ekholm B, Wick KA. Evaluation of conventional press and breathe metered-dose inhaler technique in 501 patients. J Asthma. 1994;31:193-9.

17. Jolly GP, Mohan A, Guleria R, Poulose R, George J. Evaluation of Metered Dose Inhaler Use technique and Response to Educational Training. Indian J Chest Dis Allied Sci. 2015;57:17-20. 
18. Purohit AN, Patel PP, Gandhi AM, Desai MK. An evaluation of impact of educational interventions on the technique of use of metered-dose inhaler by patients. Indian J Pharmacol. 2017;49(2):194-200.
Cite this article as: Makarani MM, Patel PP, Gandhi AM, Desai CK, Desai MK. An evaluation of the technique of use of metered dose inhaler administration in bronchial asthma children. Int $\mathbf{J}$ Basic Clin Pharmacol 2020;9:1343-50. 